\title{
CT imaging of coronavirus disease 2019 (COVID-19): from the qualitative to quantitative
}

\author{
Xiaolong $\mathrm{Qi}^{1 \#}$, Junqiang Lei ${ }^{1 \#}$, Qian $\mathbf{Y u}^{2 \#}$, Yarong $\mathrm{Xi}^{3}$, Yuancheng Wang ${ }^{2}$, Shenghong Ju ${ }^{2}$ \\ ${ }^{1}$ CHESS-COVID-19 Center, The First Hospital of Lanzhou University, Lanzhou 730000, China; ${ }^{2}$ Department of Radiology, Zhongda Hospital, \\ Medical School of Southeast University, Nanjing 210009, China; 'Department of Radiology, Longxi First People’s Hospital, Dingxi 6622203, China \\ \#These authors contributed equally to this work. \\ Correspondence to: Xiaolong Qi, MD, Professor of Medicine, CHESS-COVID-19 center, The First Hospital of Lanzhou University, Lanzhou 730000, \\ China. Email: qixiaolong@vip.163.com; Shenghong Ju, MD. Professor of Medicine, Department of Radiology, Zhongda Hospital, Medical School of \\ Southeast University, Nanjing 210009, China. Email: jsh0836@126.com.
}

Submitted Feb 18, 2020. Accepted for publication Feb 28, 2020.

doi: 10.21037/atm.2020.02.91

View this article at: http://dx.doi.org/10.21037/atm.2020.02.91

The coronavirus disease 2019 (COVID-19) from Wuhan, China has become a global challenge since the late December 2019 (1-3). The clinical characteristics of patients infected with severe acute respiratory syndrome coronavirus 2 (SARS-CoV-2) have been defined in recent studies (4-6). In addition, CT imaging characteristics have been described as an important diagnostic tool of COVID-19 (7-9). On February 4, 2020, National Health Commission of the People's Republic of China released the 5 th edition of "Diagnosis and management plan of novel coronavirus pneumonia", and highlighted the role of CT imaging in Hubei Province to promote the early detection and early isolation.

We report a 30 -year-old man presented to the hospital with a 3-day history of fever and cough of unknown cause. He indicated that he had a travel history of Wuhan, China [a potential origin of SARSCoV-2 $(1,2)]$. Real-time fluorescence polymerase-chainreaction of his respiratory specimens was positive for SARS-CoV-2 nucleic acid. At admission, unenhanced chest CT showed patchy ground-glass opacity and a few subpleural consolidations in his left lower lobe (Figure 1A). After receiving 2 days of supportive treatment, he was clinically worse and repeat chest CT showed that pneumonia progressed with distribution in bilateral lower lobes, predominantly manifesting as consolidation (Figure 1A). Therefore, therapeutic strategy was adjusted with additional treatment including interferon and antibiotic. The patient showed a good response and recovered well. Chest CT at the follow-up after 7 and 11 days showed that the pneumonia absorbed gradually (Figure 1A). During the hospitalization, radiologists provided dynamic and visible information of pulmonary lesions with three-dimensional volume-rendered reconstruction (Figure $1 \mathrm{~B}$ ). On the basis of intelligent image technology, radiologists could help the physician to monitor the progression and regression of disease using quantitative imaging information including the lesion percentage (Figure 1C) and the CT mean density values (Figure 1D) in each lung lobe. After his respiratory samples checked twice to confirm the negative of SARS-CoV-2 nucleic acid, the patient was discharged home.

In conclusion, CT imaging could play more important role on the basis of intelligent technology in managing patients of COVID-19 from diagnosis to monitoring, and from the qualitative to quantitative. 

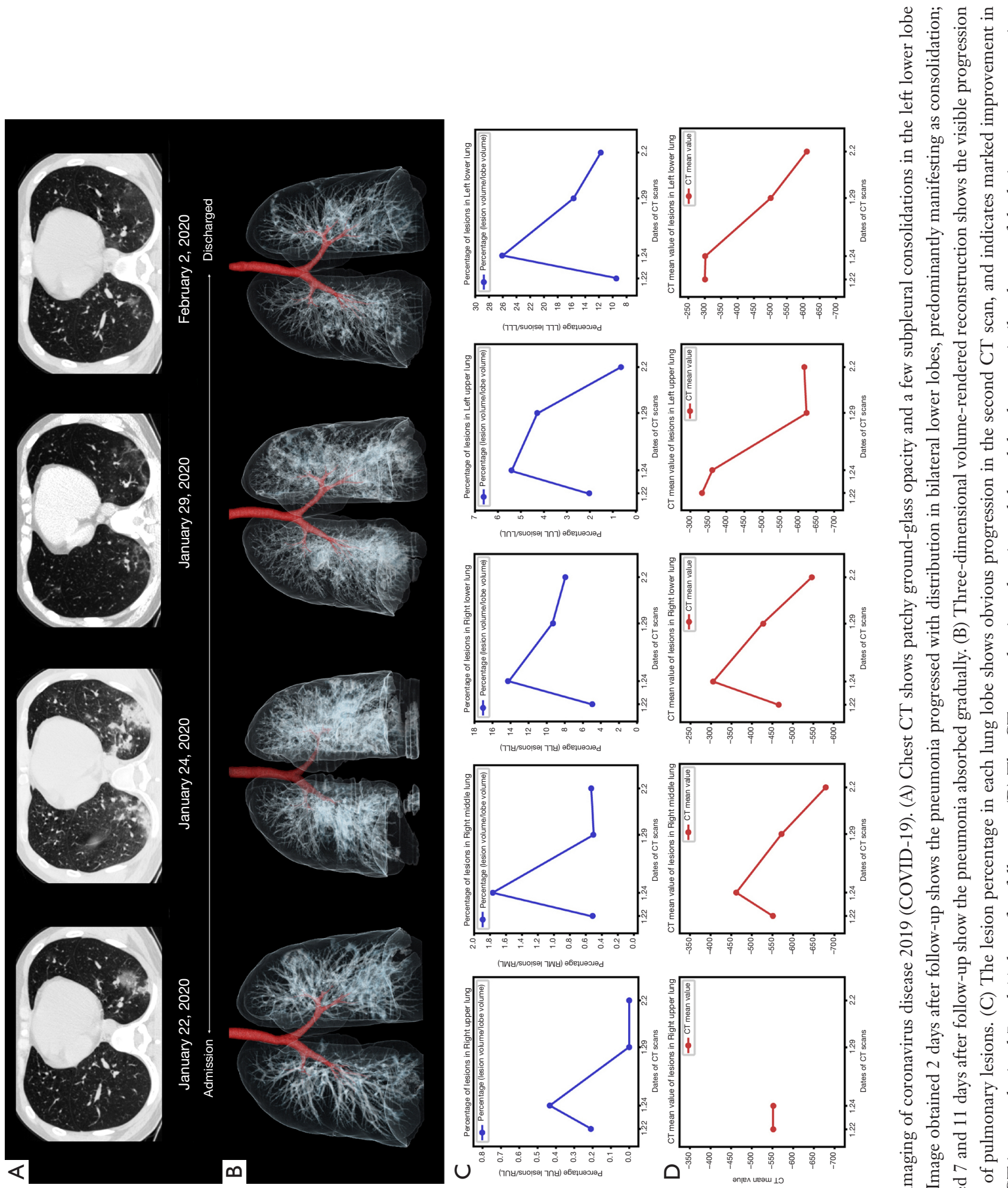

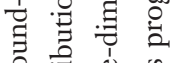

ơ

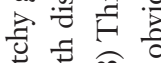

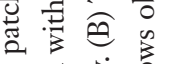

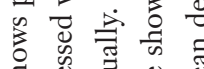

क

บ

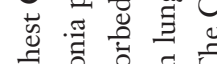

ป

¿

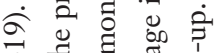

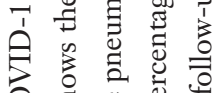

0 क

○ Ұ

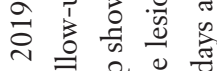

\&

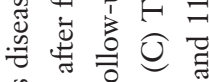

党密苛

突

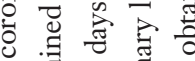

范苛

.

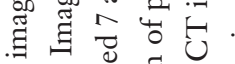

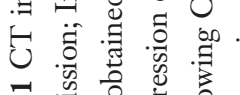

○ ق

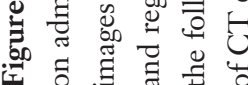




\section{Acknowledgments}

Funding: Supported by Gansu Provincial COVID-19 Science and Technology Major Project, China.

\section{Footnote}

Conflicts of Interest: The authors have no conflicts of interest to declare.

Ethical Statement: The authors are accountable for all aspects of the work in ensuring that questions related to the accuracy or integrity of any part of the work are appropriately investigated and resolved.

Open Access Statement: This is an Open Access article distributed in accordance with the Creative Commons Attribution-NonCommercial-NoDerivs 4.0 International License (CC BY-NC-ND 4.0), which permits the noncommercial replication and distribution of the article with the strict proviso that no changes or edits are made and the original work is properly cited (including links to both the formal publication through the relevant DOI and the license). See: https://creativecommons.org/licenses/by-nc-nd/4.0/.

\section{References}

1. Mattiuzzi C, Lippi G. Which lessons shall we learn from

Cite this article as: Qi X, Lei J, Yu Q, Xi Y, Wang Y, Ju S. CT imaging of coronavirus disease 2019 (COVID-19): from the qualitative to quantitative. Ann Transl Med 2020;8(5):256. doi: 10.21037/atm.2020.02.91 the 2019 novel coronavirus outbreak? Ann Transl Med 2020;8:48.

2. Zhu N, Zhang D, Wang W, et al. A Novel Coronavirus from Patients with Pneumonia in China, 2019. N Engl J Med 2020;382:727-33.

3. Li Q, Guan X, Wu P, et al. Early Transmission Dynamics in Wuhan, China, of Novel Coronavirus-Infected Pneumonia. N Engl J Med 2020. [Epub ahead of print].

4. Wang D, Hu B, Hu C, et al. Clinical Characteristics of 138 Hospitalized Patients With 2019 Novel CoronavirusInfected Pneumonia in Wuhan, China. JAMA 2020. [Epub ahead of print].

5. Chen N, Zhou M, Dong X, et al. Epidemiological and clinical characteristics of 99 cases of 2019 novel coronavirus pneumonia in Wuhan, China: a descriptive study. Lancet 2020;395:507-13.

6. Huang C, Wang Y, Li X, et al. Clinical features of patients infected with 2019 novel coronavirus in Wuhan, China. Lancet 2020;395:497-506.

7. Lei J, Li J, Li X, et al. CT Imaging of the 2019 Novel Coronavirus (2019-nCoV) Pneumonia. Radiology 2020. [Epub ahead of print].

8. Chung M, Bernheim A, Mei X, et al. CT Imaging Features of 2019 Novel Coronavirus (2019-nCoV). Radiology 2020. [Epub ahead of print].

9. Xie X, Zhong Z, Zhao W, et al. Chest CT for Typical 2019-nCoV Pneumonia: Relationship to Negative RTPCR Testing. Radiology 2020. [Epub ahead of print]. 